\title{
Survival rates of head and neck cancers in Ghana: a retrospective study at the Komfo Anokye Teaching Hospital
}

\author{
Osei Owusu-Afriyie ${ }^{1,2^{*}}$, W. K. B. A. Owiredu' ${ }^{1}$, Alexander Acheampong Oti ${ }^{5}$, Emmanuel Acheampong ${ }^{1,6}$, \\ Kwabena Owusu-Danquah ${ }^{3}$, Rita Larsen-Reindorf4 , Linda Ahenkorah Fondjo ${ }^{1}$, Evans Asamoah Adu', \\ Sampson Donkor ${ }^{1}$ and Peter Donkor ${ }^{5}$
}

\begin{abstract}
Objective: Data was collected to evaluate the survival rates of head and neck (conjunctiva, oropharyngeal and nonoropharyngeal) squamous cell carcinomas in Ghana.

Data description: We provided data on a retrospective review of 8 years (January 2004 to December 2009) survival rate of head and neck squamous cell carcinomas (HNSCCS) at the Komfo Anokye Teaching Hospital in Ghana. The data consist of patient demographic data and clinicopathological findings which includes tumour site, tumour stage and histological grades of the patients. Clinical outcome measurement was death through to January 2013 on record and confirmed from the hospitals birth and death registry department. More than $85 \%$ of death cases were confirmed by gender, age, and folder identification numbers from the birth and death registry.
\end{abstract}

Keywords: HNSCCs, Survival period, Conjunctiva, Oropharyngeal

\section{Objective}

Head and neck squamous cell carcinomas (HNSCCs) are heterogeneous tumours that develop in the oral cavity, oropharynx, hypopharynx, and larynx [1]. The incidence of HNSCCs vary broadly in Africa [2, 3] compared with that in western societies [4] largely because of wide variation in population size, economic status, ethnic origin, and belief in traditional medicine existing in Africa [5]. In Ghana, tumors of the pharynx and larynx represents $7.4 \%$ and $3.5 \%$ of all malignancies, and the second and seventh most common types of cancers, respectively seen at the National Hospital [6]. Also, data existing at the Komfo Anokye Teaching Hospital (KATH) indicate that tumors of the pharynx, larynx and oral cavity formed the largest group of HNSCCs, and most patients' presents with late-stage disease $[7,8]$.

Despite recent advances in the diagnosis and treatment of head and neck cancer, there has been little evidence of improvement in survival rates over the last few decades [9]. Independent of the numerous reports on the epidemiology and molecular characteristics of HNSCCs in Ghana, there is a dearth of data on the survival rate of patients. The first attempt at population-based cancer registration was set up in 2012 however, it would take a few years to generate survival data. Identifying the need for survival analysis, we retrospectively compiled data on HNSCCs from the pathological perspective at KATH in Ghana over a period of 8 years.

\section{Data description}

All patients referred to KATH or diagnosed by the multidisciplinary team of doctors at the facility for HNSCCs are presented at a weekly meeting to the head and neck 
Table 1 Overview of data files/data sets

\begin{tabular}{llll}
\hline Label & Name of data file/data set & File types (file extension) & Data repository and identifier (Dol or accession number) \\
\hline Data file 1 & General overview of data & MS Excel file (.xlsx) & Figshare (https://doi.org/10.6084/m9.figshare.9878258.v2) \\
Data file 2 & Cox regression analysis & MS Excel file (.xlsx) & Figshare (https://doi.org/10.6084/m9.figshare.9878258.v2) \\
Figure 1 & Survival analysis curves & tiff & Figshare (https://doi.org/10.6084/m9.figshare.9878414.v1) \\
Data set 1 & $\begin{array}{l}\text { Excel sheet of data set on HNC } \\
\text { cases from 2004-2009 }\end{array}$ & MS Excel file (.xlsx) & Figshare (https://doi.org/10.6084/m9.figshare.9878360.v2) \\
\hline
\end{tabular}

cancer clinic. As a routine management and monitoring plan, cases are discussed and a management plan decided upon. Data were obtained by retrospective review of all consecutive patient records seen at the multidisciplinary clinic from January 2004 to December 2009 and the survival probability data (Dataset 1 ) is included in Table 1 [10]. Demographic and basic health information was collected for all participants, along with pathology reports and tumor characteristics for HNSCC cases. Patient's records were reviewed and staged according to the current World Health Organization's International Classification of Disease coding system. Initial data obtained were evaluated for missing information and coded in Microsoft Excel sheet (Microsoft Office Professional Plus 2013). Overview of the Data file 1 [11] has been shown in Table 1.

For clear and concise data that clearly answer our objectives, cases with lip cancer, substitute interview data, missing covariate information, distant metastasis, and site not otherwise specified were excluded. Therefore, we limited our data curation to 299 cases alive 1 -year post-diagnosis. Outcome measurement was death through January 1, 2013 on record and confirmed from the hospitals birth and death registry department. More than $85 \%$ of death cases were confirmed by gender, age, and folder identification numbers from the birth and death registry. Survival function (Fig. 1) and cox regression analysis data (Data file 2) is also shown in Table 1 $[11,12]$. The study was approved by the Committee on Human Research and Publication Ethics, Kwame Nkrumah University of Science and Technology as well as the Ethical committee board of KATH.

\section{Limitations}

The data reflect specific patient population reporting to $\mathrm{KATH}$, thus making it an institutional-based study and may not reflect the true picture of the situation in the entire Ghana population. In addition, the data does not constitute information on the treatment regimen, clinical symptoms, and socio-demographical characteristics, however age, gender and clinicopathological features were available for analysis.

\section{Abbreviations}

HNSCCs: Head and neck squamous cell carcinomas; KATH: Komfo Anokye Teaching Hospital; HR: Hazard ratio.

\section{Acknowledgements}

We acknowledge the efforts of the multi-disciplinary team of doctors at the Head and Neck cancer clinic at the Komfo Anokye Teaching Hospital, Ghana.

\section{Authors' contributions}

Conceived and designed the techniques for data curation: OOA; WKBAO; AAO; EA; LAF; KOD; RLR. Involved in the data curation: EAA, SD, PD. Analyzed the data: OOA, EA, and EAA. Contributed materials/analysis tools: LAF, KOD, WKBAO, RLR and AAO. Wrote the paper: EA, EAA, AAO, SD, and PD. All authors read and approved the final manuscript.

\section{Funding}

No external or internal source of funding was obtained for this study.

\section{Availability of data materials}

The data described in this data note is available and can be freely and openly accessed. Refer to Table 1 for the link to each data file; Data file 1 and 2 [11],

Dataset 1 [10] Fig. 1 [12].

\section{Ethical approval and consent to participate}

The study was approved by the committee on Human Research Publication Ethics, Kwame Nkrumah University of Science and Technology. Also the ethical board at the Komfo Anokye Teaching Hospital approved.

\section{Consent for publication}

Not applicable.

\section{Competing interests}

The author declares that they have no competing interest.

\section{Author details}

${ }^{1}$ Department of Molecular Medicine, School of Medical Science, Kwame Nkrumah University of Science and Technology, Kumasi, Ghana. ${ }^{2}$ Department of Pathology, Komfo Anokye Teaching Hospital, Kumasi, Ghana. ${ }^{3}$ Department of Medical Laboratory Technology, Faculty of Allied Health, Kwame Nkrumah University of Science and Technology, Kumasi, Ghana. ${ }^{4}$ Directorate of Dental, Eye, Ear, Nose \& Throat, Komfo Anokye Teaching Hospital, Kumasi, Ghana.

${ }^{5}$ Department of Maxillofacial Surgery, Dental School, KNUST, Kumasi, Ghana.

${ }^{6}$ School of Medical and Health Science, Edith Cowan University, Joondalup, Australia.

Received: 21 September 2019 Accepted: 14 August 2020

Published online: 26 August 2020

References

1. Osei-Sarfo K, Tang XH, Urvalek AM, Scognamiglio T, Gudas L. The molecular features of tongue epithelium treated with the carcinogen 
4-nitroquinoline-1-oxide and alcohol as a model for HNSCC. Carcinogenesis. 2013;34(11):2673-81.

2. Laryea DO, Awuah B, Amoako YA, Osei-Bonsu E, Dogbe J, Larsen-Reindorf $\mathrm{R}$, et al. Cancer incidence in Ghana, 2012: evidence from a populationbased cancer registry. BMC Cancer. 2014;14(1):362.

3. Parkin DM, Bray F, Ferlay J, Pisani P. Global cancer statistics, 2002. Cancer J Clin. 2005;55(2):74-108.

4. Bray F, Ferlay J, Soerjomataram I, Siegel RL, Torre LA, Jemal A. Global cancer statistics 2018: GLOBOCAN estimates of incidence and mortality worldwide for 36 cancers in 185 countries. Cancer J Clin. 2018:68(6):394-424.

5. Sanderson RJ, Ironside JAD. Squamous cell carcinomas of the head and neck. BMJ. 2002;325(7368):822-7.

6. Calys-Tagoe BN, Yarney J, Kenu E, Amanhyia NA, Enchill E, Obeng I. Profile of cancer patients'seen at Korle Bu teaching hospital in Ghana (a cancer registry review). BMC Res Notes. 2014;7:577.

7. Owusu-Afriyie O, Owiredu W, Owusu-Danquah K, Komarck C, Foltin SK, Larsen-Reindorf $\mathrm{R}$, et al. Expression of immunohistochemical markers in non-oropharyngeal head and neck squamous cell carcinoma in Ghana. PLoS ONE. 2018;13(8):e0202790.

8. Larsen-Reindorf R, Owusu-Afriyie O, Acheampong AO, Boakye I, Awuah B. A six-year review of head and neck cancers at the Komfo Anokye
Teaching Hospital, Kumasi, Ghana. Int J Otolaryngol Head Neck Surg. 2014;3(05):271.

9. Adeyi A, Olugbenga S. The challenges of managing malignant head and neck tumors in a tropical tertiary health center in Nigeria. Pan Afr Med J. 2011;10:31.

10. Osei O-A, William KO, Alexander AO, Emmanuel A, Kwabena O-D, Rita L-R, et al. Retrospective Dataset for head and Neck Squamous cell carcinomas (2004-2009)2019.

11. Osei O-A, William KO, Alexander AO, Emmanuel A, Kwabena O-D, Rita L-R, et al. Data file 1.xlsx2019. https://doi.org/10.6084/m9.figshare.98783 60.v2

12. Osei O-A, William KO, Alexander AO, Emmanuel A, Kwabena O-D, Rita L-R, et al. Head and Neck cancer survival curves2019. https://doi.org/10.6084/ m9.figshare.9878414.v1https://doi.org/10.6084/m9.figshare.9878414.v1

\section{Publisher's Note}

Springer Nature remains neutral with regard to jurisdictional claims in published maps and institutional affiliations.
Ready to submit your research? Choose BMC and benefit from:

- fast, convenient online submission

- thorough peer review by experienced researchers in your field

- rapid publication on acceptance

- support for research data, including large and complex data types

- gold Open Access which fosters wider collaboration and increased citations

- maximum visibility for your research: over $100 \mathrm{M}$ website views per year

At $\mathrm{BMC}$, research is always in progress.

Learn more biomedcentral.com/submissions 